\title{
Quantitative Assessment of Permissible Loads on Georgia's Soil
}

\author{
David Kereselidze', Lia Matchavariani ${ }^{2, ~ *, ~ V a z h a ~ T r a p a i d z e ', ~ L a m z i r a ~ L a g i d z e ~}{ }^{3}$, David Svanadze \\ Giorgi Bregvadze', Zaal Gulashvili ${ }^{1}$ \\ ${ }^{1}$ Department of Hydrometeorology, Faculty of Exact \& Natural Sciences, Ivane Javakhishvili Tbilisi State University, Tbilisi, Georgia \\ ${ }^{2}$ Department of Soil Geography, Faculty of Exact \& Natural Sciences, Ivane Javakhishvili Tbilisi State University, Tbilisi, Georgia \\ ${ }^{3}$ Department of Nature Use Management, Faculty of Exact \& Natural Sciences, Ivane Javakhishvili Tbilisi State University, Tbilisi, Georgia \\ ${ }^{4}$ Department of Geography, Faculty of Exact \& Natural Sciences, Ivane Javakhishvili Tbilisi State University, Tbilisi, Georgia
}

\section{Email address:}

david.kereselidze@tsu.ge (D. Kereselidze), lia.matchavariani@tsu.ge (L. Matchavariani), v.trapaidze@yahoo.com (V. Trapaidze), lagidze_1@rocketmail.com (L. Lagidze), datosvani@posta.ge (D. Svanadze), gbregvadze76@gmail.com (G. Bregvadze)

\section{To cite this article:}

David Kereselidze, Lia Matchavariani, Vazha Trapaidze, Lamzira Lagidze, David Svanadze, Giorgi Bregvadze, Zaal Gulashvili. Quantitative Assessment of Permissible Loads on Georgia's Soil. American Journal of Environmental Protection. Special Issue: Applied Ecology:

Problems, Innovations. Vol. 4, No. 3-1, 2015, pp. 29-33. doi: 10.11648/j.ajep.s.2015040301.15

\begin{abstract}
Environment, including different types of soils, is permanently influenced by human activity, natural and technogenic disasters, etc. These influences weaken stability of ecosystems, landscapes, soils, especially in the case when these influences exceed the value of the maximum permissible standard. Every natural effect causes weakening of soil stability. That's why it is important to know the values of the lads, which cause failure of proper functioning of soils. At present averaged values of observation data are considered as maximum permissible norms of different loads on soils. In the meantime, actual indices of soil loads are stipulated by many variable factors. Existing standards of permissible loads on soil don't meet requirements, which provide proper functioning. Additional demands, related through time to operating conditions and probabilistic-statistical characterizing of factors causing processes of soil degradation in time, must be raised upon actual standards. Absence of scientifically substantiated permissible load norms is a reason of soil erosion that as the final result leads to land depopulation and loss of ethno-cultural traditions. That's why in the given work take into account factors, which cause regulatory values of parameters of soil loads. Time of possible loss, fertility to the marginal degradation was calculated for all main types of Georgia's soils.
\end{abstract}

Keywords: Loss Fertility, Soils, Calculation, Georgia

\section{Introduction}

Observations on natural environment show that in the era of modern industrial development the nature experiences various kinds of the undesirable effects, and as a result deterioration of its conditions takes place, it degrades. Disturbances and certain changes of the natural environment are the elements of united global processes. That's why both common physical laws and individual regularities caused by specific indicators of separate elements are clearly reflected in geographic system and its elements. Temporal and space variability of indicators best of all determines the condition of the Environment and threat of hazard risks.

Accurate quantitative assessment of environmental condition is almost impossible, that's why the application of approximation methods is acceptable, to which end is necessary to use the current mathematical possibilities and select the most appropriate model, which makes possible a problem solving using a valid approximation.

The environment consists of a great number of elements, which are accompanied also by a great many processes; it is desirable, but virtually impossible to take into account all these elements, that's why it is important to select the basic elements, which play the leading role in the environment's functioning.

In our case a soil has been selected as the basic element of the environment, since the existence and future of mankind are directly related to it.

The work objective is a quantitative assessment of condition of fertile soils of Georgia and elaboration of 
approximation (probable) methods for calculation of risks of hazardous undesirable situations.

The necessity of these methods is driven by soil preservation with minimal losses that in its turn will promote harmonic coexistence of mankind with environment and radical improvement of the current situation.

\section{Research Method}

Soil, as well as natural environment consists of a great number of elements and processes, which accompany these elements. Consequently, disordered motion permanently occurs in the soil, which in this regard is similar to Brownian motion, which is usually studied using stochastic kinematic equations.

The process of soil functioning can be described by Kiyoshi Ito's stochastic differential equation $[13,14]$ :

$$
d y(t)=m_{0}(t) d t+\delta(t) d x(t)
$$

where $y(t)$ is soil depth, $m_{0}(t)$ and $\delta(t)$ are average rate and mean square deviation of soil depth variability, $x(t)$ is a random value of Gaussian process.

Equation (1) can be rewritten as follows:

$$
d y=m d t+\delta d x(t)
$$

Equation (2), which describes variation of soil depth leads us to diffusive distribution of soil during its permanent functioning, which under certain conditions is represented by the solution of Fokker-Planck-Kolmogorov equation:

$$
\frac{\partial P}{\partial t}+m \frac{\partial P}{\partial y}-\frac{\delta^{2}}{2} \frac{\partial^{2} P}{\partial y^{2}}=0
$$

Fokker-Planck-Kolmogorov equation according to classification of partial differential equations is an equation of parabolic form. For its solution, it is necessary to know initial and boundary conditions of a given function, and namely boundary conditions determine the form of a solution of equation (3).

When implementation of process (2) is by monotonous nature, boundary and initial conditions are of the following form:

$$
\begin{gathered}
P(y, t)=|y=-\infty=P(y, t)|_{y=\infty}^{0} \\
P(y, t)=\left.\right|_{y=0=\delta(y)}
\end{gathered}
$$

where $\delta_{(y)}$ is delta-function.

Solution of equation (3) with conditions (4) and (5) is known as fundamental and they are of following form:

$$
p=\frac{1}{\delta \sqrt{2 \pi t}} \exp \left[+\frac{(y-\mu t)^{2}}{2 \delta^{2} t}\right]
$$

Here parameter $\mu$, which represents a comparison of the admissible limit value of soil depth with an average rate of soil depth variability.

The density of a transient diffusive kind is precisely described by differential equations. Since soil degradation is caused by the continuous action of external factors, variability of random processes will be of monotonous nature. Proceeding from this fact we can suppose that soil degradation process is of the monotonous nature with an average rate $(\mathrm{m})$ and mean square deviation $(\delta)$ of persistent variables.

Trouble-free operation of soil during degradation $p(t)$ is the same as a probability of failure of the undesirable condition, or soil reliability during t time $[7,13,14]$.

$$
P(t)=\Phi\left(\frac{t-\mu}{\alpha \mu \sqrt{t}}\right)
$$

From the standpoint of theory of reliability a functional possibility of happening of undesirable situation can be characterized by areas of limit states, beyond of which, as it is considered, a soil have a failure. Generally a violation of conditions of soil functioning is considered as soil failure. Mathematical expectation $m(t)$ and dispersion $\delta_{t}^{2}$ of failure of undesirable condition are calculated using the following formulas:

$$
\begin{gathered}
M_{t}=\mu\left(1+\frac{\mu \alpha^{2}}{2}\right) \\
\delta_{t}^{2}=\mu^{3} \alpha^{2}\left(1+\frac{5 \mu \alpha^{2}}{4}\right)
\end{gathered}
$$

where: $\mu=\frac{I_{r}}{m} \quad$ and $\alpha=\frac{\delta}{\sqrt{I_{r} m}}$.

When using normed random variable $Z$ [8], the expression (7) will be as follows:

$$
\frac{\mu-t}{\alpha \mu \sqrt{t}}=Z
$$

In this case $\mathrm{Z}$ is a static reserve of resistivity $Z=R-P$, which causes the probability of trouble-free operation of soil.

Time, in the course of which a soil reaches the boundary (limit) value $I_{r}$ of degradation, can be determined by squaring of equation (10) and afterwards by solution of receiving quadratic equation.

$$
t^{2}-\left(2+Z^{2} V^{2}\right) \mu+\mu^{2}=0
$$


where $V=\frac{\delta^{2}}{m^{2}}$

$$
t=\mu\left[\frac{2+Z^{2} V^{2} \pm \sqrt{\left(4+Z^{2} V^{2}\right)^{2} \cdot V^{2} Z^{2}}}{2}\right]
$$

By means of formula (12) it is possible to determine the degradation rate for the soil.

Similarly, we know that $\mu=\frac{I_{r}}{m}$, so we can determine $Z_{v}$ :

$$
I_{r}=\frac{2 t m}{\left(2+V^{2} Z^{2}\right)-\sqrt{V^{2} Z^{2}\left(2+V^{2} Z^{2}\right)}}
$$

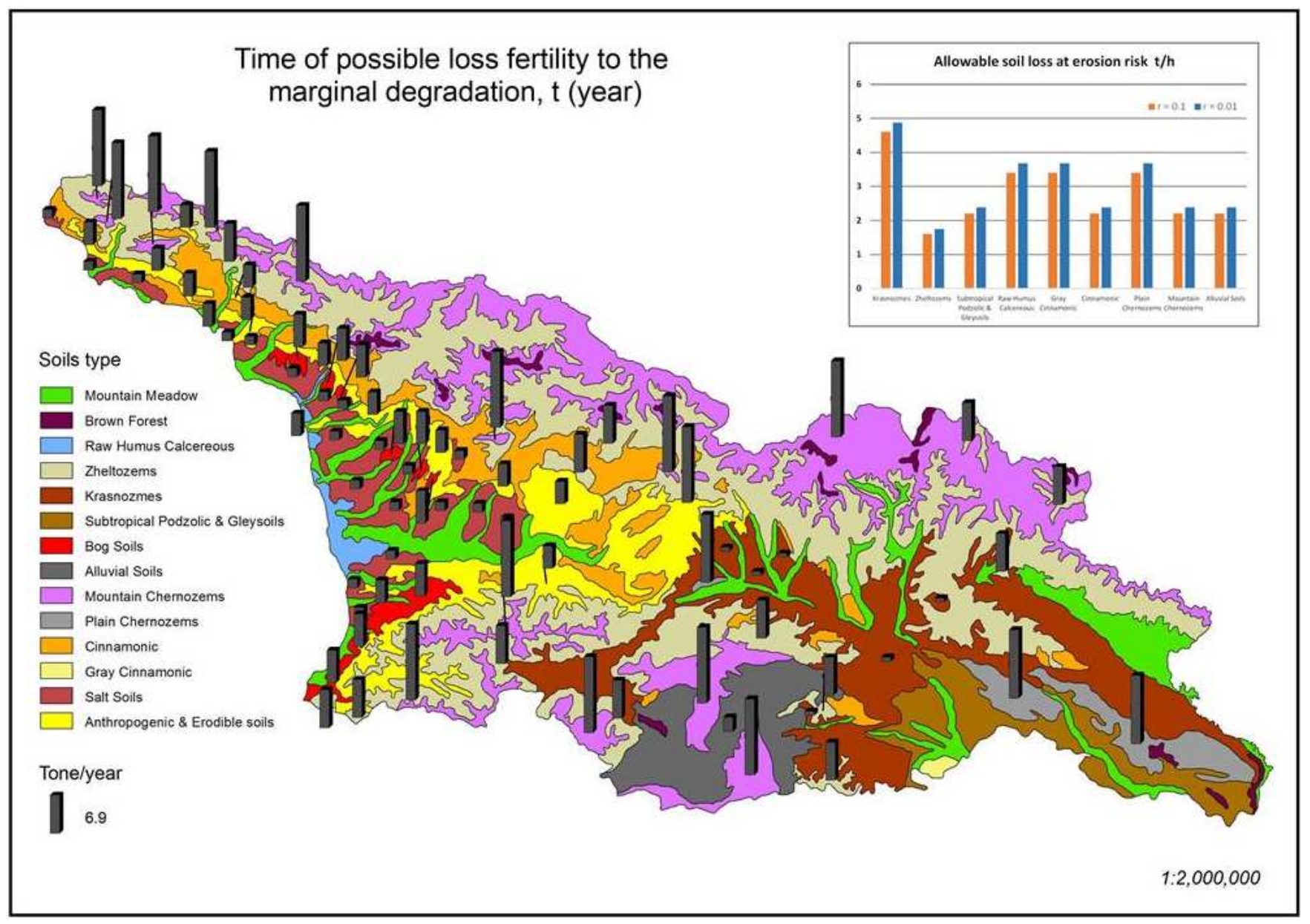

Figure 1. Time of possible loss of soil fertility to the marginal degradation, $t$ (year)

\section{Results}

As we mentioned above, time, during which soil reaches boundary values of degradation, is calculated according to the formula (12). Humus percentage was selected as a determining parameter of soil degradation. The average rate of its variability was determined on the basis of following consideration that deep-earth irreversible soil transformations vary from 2-3 minutes from $8-10$ minutes, i.e. 5 years in average $[3,4]$, the mean square deviation of average rate of variation of humus percentage $\delta$ is calculated by means of observation data processing, if they are not available, then using approximation methods of mathematical statistics [15]. Approximate mean square deviation is simple and quickly determined with the use of following formula (14):

$$
\delta=\frac{X_{\max }-X_{\min }}{K}
$$

where, $X_{\max }, X_{\min }$ in our case are maximum and minimum values of humus percentage in the soil; $\mathrm{K}-$ coefficient, which is depended on the number $\mathrm{n}$ of observed data.

For the first time this method was offered by Tippet [15], table 1.

Determination of permissible rates of soil degradation makes possible the soil protection from catastrophic washouts, which have tended to grow. At the same time by their means it is possible to formulate criteria of the decision making, with the use of which soil protection and recovery measures will be planned. 
Researchers have been carried out at the various types of Georgian soils in order to determine permissible rates of soil degradation. Studies gave us the following results: if the duration of soil existence is 1000 years, while humic layer depth is $20 \mathrm{~cm}$, then maximum permissible soil losses within the risk limits $0,01<r<0,1$ are calculated by following formula $[5,10,11,12]$.

$$
H_{0}=\frac{H_{0}-\delta_{H_{0}} H_{0}-H_{D}}{t}
$$

where $H_{0}$ is the initial soil resource; $H_{D}$ is a maximum permissible rate of soil degradation; $\delta_{H_{0}}$ is the mean square deviation of initial soil resources. Obtained data are given in the table, and on the basis of these data the map for permissible soil losses in Georgia is compiled (figure 1).

The time during which an each soil reaches limit values of degradation, was determined according to a formula (12) and using above mentioned approximation methods of mathematical statistics. These values are given in table 2 .

Table 1. Calculation of the K coefficient, which is depending on the number $n$ of observed data [15]

\begin{tabular}{|c|c|c|c|c|c|c|c|c|c|c|}
\hline$n$ & 0 & 1 & 2 & 3 & 4 & 5 & 6 & 7 & 8 & 9 \\
\hline 0 & - & - & 1.12 & 1.69 & 2.05 & 2.32 & 2.53 & 2.7 & 2.84 & 2.97 \\
\hline 10 & 3.07 & 3.17 & 3.25 & 3.33 & 3.40 & 3.47 & 3.53 & 3.58 & 3.64 & 3.69 \\
\hline
\end{tabular}

Table 2. Limit values of soil degradation

\begin{tabular}{|c|c|c|c|c|c|c|}
\hline & Soil type & Soil depth, cm & $\begin{array}{c}\text { Profile } \\
\text { humification, } \\
\mathbf{c m}\end{array}$ & 竎 & Absolute altitude $\mathrm{z}, \mathrm{dm}$ & 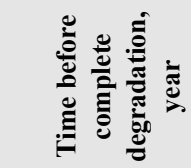 \\
\hline 1 & Mountain-meadow soils & Small 50-80 & $\begin{array}{l}\text { average \& small, } \\
10-20\end{array}$ & $\begin{array}{l}5-10 \\
15-20\end{array}$ & $\begin{array}{l}\text { 1800-2800 West Georgia } \\
2000-3500 \text { East Georgia }\end{array}$ & 13.8 \\
\hline 2 & Mountain-forest-meadow soils & Small 50-80 & $\begin{array}{l}\text { average \& small, } \\
10-20\end{array}$ & $4-8$ & $1800-2600$ & 3.6 \\
\hline 3 & $\begin{array}{l}\text { Mountain-meadow-chernozem } \\
\text {-like }\end{array}$ & small or average $70-80$ & deep, 20-30 & $8-12$ & above $1800(2000)$ & 5.5 \\
\hline 4 & Brown forest soils & Average $50-100$ & average, $15-20$ & $5-10$ & $\begin{array}{l}\text { 800-2000 West Georgia } \\
900-2000 \text { East Georgia }\end{array}$ & 6.9 \\
\hline 5 & Black, brown forest soil & Small 60-90 & too deep, $40-50$ & $4-9$ & $1100-1600$ & 6.2 \\
\hline 6 & Raw Humic Calcereous soils & Average $100-150$ & $\begin{array}{l}\text { clearly expressed, } \\
15-20\end{array}$ & $2-5$ & $400(600)-1600(1800)$ & 1.6 \\
\hline 8 & Plain Chernozems & deep & deep, 40-50 & $5-15$ & $60-650$ & 12.1 \\
\hline 9 & Cinnamonic soils & average or small & $\begin{array}{l}\text { average \& deep, } \\
20-35\end{array}$ & $2.5-3.5$ & $\begin{array}{l}500(700)- \\
900(1300)\end{array}$ & 0.74 \\
\hline 10 & Meadow cinnamonic soils & deep & deep, 20-30 & $2-3$ & $500-900$ & 0.60 \\
\hline 11 & Gray-cinnamonic soils & Deep 150-200 & deep, $20-30$ & $2-3$ & $650-700$ & 0.60 \\
\hline 12 & Meadow Gray & Deep 150-200 & $\begin{array}{l}\text { average \& small, } \\
10-15\end{array}$ & $1-2$ & $135-200$ & 0.42 \\
\hline 13 & Salt soils & Deep 150-200 & small, $10-15$ & $1-1.5$ & $135-700$ & 5,9 \\
\hline 14 & Krasnozems & deep & deep, $20-40$ & $3-10$ & $300-500$ & 17,9 \\
\hline 15 & Zheltozems (Yellow Soils) & average and deep & $\begin{array}{l}\text { average \& small, } \\
10-15\end{array}$ & $5-9$ & $500-700$ & 4.1 \\
\hline 16 & Subtropical Podzolic soils & average and small & average, $15-20$ & $2-5$ & $30-200$ & 1.6 \\
\hline 17 & Podzolic-Gley soils & average and small & average, $15-20$ & $3-5$ & up to 100 & 1.3 \\
\hline 18 & Bog soils & Deep 150 & $\begin{array}{l}\text { average \& deep, } \\
15-20\end{array}$ & $10-15$ & up to 50 & \\
\hline
\end{tabular}

\section{Conclusions}

Offered method, based on the theory of reliability makes possible the forecasting of soil degradation with the use of a minimal amount of initial data and doesn't require complicated calculations, that makes it easy-to-use under actual operation conditions.
The elaborated approach of forecasting of degradation processes gives us an opportunity to optimize the parameters of different soils for tolerant value of risk of origination of the unfavorable state of soil as a result of degradation.

Given the data of observations on changes of soil properties under the influence of anthropogenic and other factors, the offered method will make possible the forecasting of the degradation process with approximation sufficient for 
practice.

The method offered for forecasting of risk of origination of the unfavorable state of soils is sufficient for reasonable conclusion on the expediency of soil use for different purposes.

Growing rates of soil degradation under different influences require the fast formation of new areas of scientific knowledge on soil degradation, which, hopefully, will become a one of the basic fields of soil science.

The authors are aware that for the offered method the following fact is important. Since this method has no restrictions it can be used for the solution of other tasks such as: assessment of ecological sustainability of soils having global biospheric importance, sustainability of soil systems and for other goals.

\section{References}

[1] A.G. Bondarev, I.B. Kuznetsov, Problems of degradation of physical properties of soils in Russia and ways of their solution, Eurasian Soil Science, №9, 1999, 1126-1131.

[2] G.B. Dobrovolsky, U.D. Nikitin, Soil function in biosphere and ecosystems, M. Nauka, 1990, 260.

[3] B.A. Zimovets, N.B. Khitrov, G.N. Kochetkova, N.P. Chizhikova, Assessment of degradation of irrigated soils, Eurasian Soil Science, №9, 1998, 1119-1126.

[4] B.A.Zimovets, Ecology and melioration of soils of dry steppe zone, V.V. Dokuchaev Institute of Soils, Moscow, 1991, 249.

[5] D.N. Kereselidze, L.G. Machavariani, B.B. Kalandadze, V.Z. Trapaidze, Permissible rates of Georgian soil losses during erosions, Eurasian Soil Science, №4, 2013, 438-446
[6] M.S. Kuznetsov, G.P. Glazunov, Erosion and soil protection, Moscow, MSU Publishing House, 1991, 334.

[7] A.N. Kolmogorov, On analytical method in the theory of probability, Successes of mathematical sciences, Issue 5, 1938.

[8] I. Likesh, I. Lyacha, Basic tables of mathematical statistics, Finansy i Statistika (Finances and Statistics), Moscow, 1985, 356.

[9] Ts.E. Mirtskhulava, Quantitative assessment of maximum permissible landscape loads, Bulletins of RAS, Geographic Series, Moscow, №3, 2001, 68-74.

[10] Ts.E. Mirtskhulava, Soil degradation and ways of forecasting of undesirable conditions during irrigation, Eurasian Soil Science, № 12, 2001, 1503-1510.

[11] Ts.E. Mirtskhulava, Hazards and risks in some water and other systems, Tbilisi, Nauka (Science), 2003, 540.

[12] Ts.E. Mirtskhulava, Environmental disturbance (forecasting of disturbance risk), Measures on its reduction, Institute of Hydroecology of GNAS, Tbilisi, 1993, 438.

[13] L.L. Sveshnikov, Applied methods of theory of random functions, M. Nauka, 1968, 512.

[14] S.B. Pogrebinsky, V.P. Strelnikov, Designing and reliability of multiprocessor computers, M. Radio i svyaz (Radio and communication), 1998, 168 .

[15] N.A. Tolokontsev, Calculation of mean square deviation, Procceedings of the third meeting on application of mathematical methods in biology, Publishing house of Leningrad University, Leningrad, 1961, 83- 93

[16] R.P.C. Morgan, Soil Erosion and Conservation, Blackwell Publishing, USA, 2005, 304. 